\title{
Common fixed points for $(\psi, \alpha, \beta)$-weakly contractive mappings in generalized metric spaces
}

\author{
Hüseyin $|s ̧| k^{1,2^{*}}$ and Duran Türkoğlu $u^{1,3}$
}

\section{"Correspondence:}

huseyinisik@gazi.edu.tr

'Department of Mathematics,

Faculty of Science, University of

Gazi, Teknikokullar, Ankara 06500, Turkey

${ }^{2}$ Department of Mathematics, Muş Alparslan University, Muş, 49100,

Turkey

Full list of author information is available at the end of the article

\begin{abstract}
We establish some common fixed point theorems for mappings satisfying a $(\psi, \alpha, \beta)$-weakly contractive condition in generalized metric spaces. Presented theorems extend and generalize many existing results in the literature.

MSC: Primary $54 \mathrm{H} 25$; secondary $47 \mathrm{H} 10$
\end{abstract}

Keywords: fixed point; generalized metric; weakly contractive condition; contraction of integral type; common fixed points

\section{Introduction and preliminaries}

In 2000, Branciari [1] introduced the concept of a generalized metric space where the triangle inequality of a metric space was replaced by an inequality involving three terms instead of two. As such, any metric space is a generalized metric space, but the converse is not true [1]. He proved the Banach fixed point theorem in such a space. After that, many fixed point results have been established for this interesting space. For more, the reader can refer to [2-12].

It is also known that common fixed point theorems are generalizations of fixed point theorems. Recently, many researchers have interested in generalizing fixed point theorems to coincidence point theorems and common fixed point theorems. In a recent paper, Choudhury and Kundu [13] established the $(\psi, \alpha, \beta)$-weak contraction principle to coincidence point and common fixed point results in partially ordered metric spaces.

The purpose of this paper is to extend the results in [13] to the set of generalized metric spaces.

Definition 1 ([1]) Let $X$ be a non-empty set and let $d: X \times X \rightarrow[0,+\infty)$ be a mapping such that for all $x, y \in X$ and for all distinct points $u, v \in X$, each of them different from $x$ and $y$, one has

(i) $d(x, y)=0$ if and only if $x=y$,

(ii) $d(x, y)=d(y, x)$,

(iii) $d(x, y) \leq d(x, u)+d(u, v)+d(v, y)$ (the rectangular inequality).

Then $(X, d)$ is called a generalized metric space (or for short g.m.s.).

Definition 2 ([1]) Let $(X, d)$ be a g.m.s., let $\left\{x_{n}\right\}$ be a sequence in $X$ and $x \in X$. 
(i) We say that $\left\{x_{n}\right\}$ is a g.m.s. convergent to $x$ if and only if $d\left(x_{n}, x\right) \rightarrow 0$ as $n \rightarrow+\infty$. We denote this by $x_{n} \rightarrow x$.

(ii) We say that $\left\{x_{n}\right\}$ is a g.m.s. Cauchy sequence if and only if for each $\varepsilon>0$ there exists a natural number $n(\varepsilon)$ such that $d\left(x_{n}, x_{m}\right)<\varepsilon$ for all $n>m>n(\varepsilon)$.

(iii) $(X, d)$ is called a complete g.m.s. if every g.m.s. Cauchy sequence is g.m.s. convergent in $X$.

We denote by $\Psi$ the set of functions $\psi:[0,+\infty) \rightarrow[0,+\infty)$ satisfying the following hypotheses:

$(\psi 1) \psi$ is continuous and monotone nondecreasing,

$(\psi 2) \psi(t)=0$ if and only if $t=0$

We denote by $\Phi$ the set of functions $\alpha:[0,+\infty) \rightarrow[0,+\infty)$ satisfying the following hypotheses:

$(\alpha 1) \alpha$ is continuous,

$(\alpha 2) \alpha(t)=0$ if and only if $t=0$.

We denote by $\Gamma$ the set of functions $\beta:[0,+\infty) \rightarrow[0,+\infty)$ satisfying the following hypotheses:

$(\beta 1) \quad \beta$ is lower semi-continuous,

( $\beta 2) \quad \beta(t)=0$ if and only if $t=0$.

\section{Main results}

Definition 3 ([14]) Let $X$ be a non-empty set and let $T, F: X \rightarrow X$. The mappings $T, F$ are said to be weakly compatible if they commute at their coincidence points, that is, if $T x=F x$ for some $x \in X$ implies that $T F x=F T x$.

Lemma 1 Let $\left\{a_{n}\right\}$ be a sequence of non-negative real numbers. If

$$
\psi\left(a_{n+1}\right) \leq \alpha\left(a_{n}\right)-\beta\left(a_{n}\right)
$$

for all $n \in \mathbb{N}$, where $\psi \in \Psi, \alpha \in \Phi, \beta \in \Gamma$ and

$$
\psi(t)-\alpha(t)+\beta(t)>0 \text { for all } t>0
$$

then the following hold:

(i) $a_{n+1} \leq a_{n}$ if $a_{n}>0$,

(ii) $a_{n} \rightarrow 0$ as $n \rightarrow+\infty$.

Proof (i) Let, if possible, $a_{n}<a_{n+1}$ for some $n \in \mathbb{N}$. Then, using the monotone property of $\psi$ and (2.1), we have

$$
\psi\left(a_{n}\right) \leq \psi\left(a_{n+1}\right) \leq \alpha\left(a_{n}\right)-\beta\left(a_{n}\right)
$$

which implies that $a_{n}=0$ by (2.2), a contradiction with $a_{n}>0$. Therefore, for all $n \in \mathbb{N}$,

$$
a_{n+1} \leq a_{n}
$$


(ii) By (i) the sequence $\left\{a_{n}\right\}$ is non-increasing, hence there is $a \geq 0$ such that $a_{n} \rightarrow a$ as $n \rightarrow+\infty$. Letting $n \rightarrow+\infty$ in (2.1), using the lower semi-continuity of $\beta$ and the continuities of $\psi$ and $\alpha$, we obtain $\psi(a) \leq \alpha(a)-\beta(a)$, which by (2.2) implies that $a=0$.

Theorem 1 Let $(X, d)$ be a Hausdorff and complete g.m.s. and let $T, F: X \rightarrow X$ be selfmappings such that $T X \subseteq F X$, and $F X$ is a closed subspace of $X$, and that the following condition holds:

$$
\psi(d(T x, T y)) \leq \alpha(d(F x, F y))-\beta(d(F x, F y))
$$

for all $x, y \in X$, where $\psi \in \Psi, \alpha \in \Phi, \beta \in \Gamma$ and satisfy condition (2.2). Then $T$ and $F$ have a unique coincidence point in $X$. Moreover, if $T$ and $F$ are weakly compatible, then $T$ and $F$ have a unique common fixed point.

Proof Let $x_{0}$ be an arbitrary point in $X$. Since $T X \subseteq F X$, we can define the sequence $\left\{x_{n}\right\}$ in $X$ by

$$
T x_{n}=F x_{n+1} \quad \text { for all } n \geq 0 \text {. }
$$

Substituting $x=x_{n}$ and $y=x_{n+j}$ for every $j \in \mathbb{N}$ in (2.3), using (2.4), we have

$$
\begin{aligned}
\psi\left(d\left(T x_{n}, T x_{n+j}\right)\right) & \leq \alpha\left(d\left(F x_{n}, F x_{n+j}\right)\right)-\beta\left(d\left(F x_{n}, F x_{n+j}\right)\right) \\
& =\alpha\left(d\left(T x_{n-1}, T x_{n+j-1}\right)\right)-\beta\left(d\left(T x_{n-1}, T x_{n+j-1}\right)\right) .
\end{aligned}
$$

By (ii) of Lemma 1, we obtain that

$$
\lim _{n \rightarrow+\infty} d\left(T x_{n}, T x_{n+j}\right)=0
$$

Next we prove that $\left\{T x_{n}\right\}$ is a g.m.s. Cauchy sequence. Suppose that $\left\{T x_{n}\right\}$ is not a g.m.s. Cauchy sequence. Then there exists $\varepsilon>0$, for which we can find subsequences $\left\{T x_{m_{k}}\right\}$ and $\left\{T x_{n_{k}}\right\}$ of $\left\{T x_{n}\right\}$ with $n_{k}>m_{k}>k$ such that

$$
d\left(T x_{n_{k}}, T x_{m_{k}}\right) \geq \varepsilon
$$

Further, corresponding to $m_{k}$, we can choose $n_{k}$ in such a way that it is the smallest integer with $n_{k}>m_{k}$ satisfying (2.6). Then

$$
d\left(T x_{n_{k}-1}, T x_{m_{k}}\right)<\varepsilon .
$$

Now, using (2.6), (2.7) and the rectangular inequality, we have

$$
\begin{aligned}
\varepsilon & \leq d\left(T x_{n_{k}}, T x_{m_{k}}\right) \\
& \leq d\left(T x_{n_{k}}, T x_{n_{k}-2}\right)+d\left(T x_{n_{k}-2}, T x_{n_{k}-1}\right)+d\left(T x_{n_{k}-1}, T x_{m_{k}}\right) \\
& <d\left(T x_{n_{k}}, T x_{n_{k}-2}\right)+d\left(T x_{n_{k}-2}, T x_{n_{k}-1}\right)+\varepsilon .
\end{aligned}
$$


Letting $k \rightarrow+\infty$ in the above inequality, using (2.5) with $j=1,2$, we obtain

$$
\lim _{k \rightarrow+\infty} d\left(T x_{n_{k}}, T x_{m_{k}}\right)=\varepsilon
$$

Again, the rectangular inequality gives us

$$
\begin{aligned}
& d\left(T x_{n_{k}}, T x_{m_{k}}\right) \leq d\left(T x_{n_{k}}, T x_{n_{k}-1}\right)+d\left(T x_{n_{k}-1}, T x_{m_{k}-1}\right)+d\left(T x_{m_{k}-1}, T x_{m_{k}}\right) \\
& d\left(T x_{n_{k}-1}, T x_{m_{k}-1}\right) \leq d\left(T x_{n_{k}-1}, T x_{n_{k}}\right)+d\left(T x_{n_{k}}, T x_{m_{k}}\right)+d\left(T x_{m_{k}}, T x_{m_{k}-1}\right) .
\end{aligned}
$$

Taking $k \rightarrow+\infty$ in the above inequalities and using (2.5) and (2.8), we get

$$
\lim _{k \rightarrow+\infty} d\left(T x_{n_{k}-1}, T x_{m_{k}-1}\right)=\varepsilon
$$

Substituting $x=x_{n_{k}}$ and $y=x_{m_{k}}$ in (2.3), we have

$$
\begin{aligned}
\psi\left(d\left(T x_{n_{k}}, T x_{m_{k}}\right)\right) & \leq \alpha\left(d\left(F x_{n_{k}}, F x_{m_{k}}\right)\right)-\beta\left(d\left(F x_{n_{k}}, F x_{m_{k}}\right)\right) \\
& =\alpha\left(d\left(T x_{n_{k}-1}, T x_{m_{k}-1}\right)\right)-\beta\left(d\left(T x_{n_{k}-1}, T x_{m_{k}-1}\right)\right) .
\end{aligned}
$$

Letting $k \rightarrow+\infty$ in (2.10) and using the lower semi-continuity of $\beta$ and the continuities of $\psi$ and $\alpha$, we obtain

$$
\psi(\varepsilon) \leq \alpha(\varepsilon)-\beta(\varepsilon)
$$

which implies that $\varepsilon=0$ by (2.2), a contradiction with $\varepsilon>0$. It then follows that $\left\{T x_{n}\right\}$ is a g.m.s. Cauchy sequence, and hence $\left\{T x_{n}\right\}$ is convergent in the complete g.m.s. $(X, d)$. Since $F X$ is closed and by (2.4), $T x_{n}=F x_{n+1}$ for all $n \geq 0$, we have that there exists $w \in F X$ for which

$$
\lim _{n \rightarrow+\infty} F x_{n}=\lim _{n \rightarrow+\infty} T x_{n}=w .
$$

We can find $y$ in $X$ such that $F y=w$. From (2.3), we get

$$
\begin{aligned}
\psi\left(d\left(F x_{n+1}, T y\right)\right) & =\psi\left(d\left(T x_{n}, T y\right)\right) \\
& \leq \alpha\left(d\left(F x_{n}, F y\right)\right)-\beta\left(d\left(F x_{n}, F y\right)\right) .
\end{aligned}
$$

On taking limit as $n \rightarrow+\infty$ and using (2.11), we have

$$
\psi(d(w, T y)) \leq \alpha(0)-\beta(0),
$$

which implies that $\psi(d(w, T y))=0$, and $T y=w$. Then we obtain

$$
w=F y=T y .
$$

Therefore, $w$ is a point of coincidence of $T$ and $F$. The uniqueness of the point of coincidence is a consequence of condition (2.3). 
Now, we show that there exists a common fixed point of $T$ and $F$. Since $T$ and $F$ are weakly compatible, by (2.12), we have that $T F y=F T y$, and

$$
T w=T F y=F T y=F w .
$$

If $y=w$, then $y$ is a common fixed point. If $y \neq w$, then by (2.3) we have

$$
\begin{aligned}
\psi(d(F y, F w)) & =\psi(d(T y, T w)) \\
& \leq \alpha(d(F y, F w))-\beta(d(F y, F w)) .
\end{aligned}
$$

From (2.2), $F y=F w$. Then, by (2.12) and (2.13), we have $w=F w=T w$. Consequently, $w$ is the unique common fixed point of $T$ and $F$.

Denote by $\Lambda$ the set of functions $\gamma:[0,+\infty) \rightarrow[0,+\infty)$ satisfying the following hypotheses:

$\left(h_{1}\right) \quad \gamma$ is a Lebesgue-integrable mapping on each compact of $[0,+\infty)$.

$\left(h_{2}\right)$ For every $\varepsilon>0$, we have

$$
\int_{0}^{\varepsilon} \gamma(s) d s>0
$$

We have the following result.

Theorem 2 Let $(X, d)$ be a Hausdorff and complete g.m.s. and let $T, F: X \rightarrow X$ be selfmappings such that $T X \subseteq F X$, and FX is a closed subspace of $X$, and that the following condition holds:

$$
\int_{0}^{d(T x, T y)} \gamma_{1}(s) d s \leq \int_{0}^{d(F x, F y)} \gamma_{2}(s) d s-\int_{0}^{d(F x, F y)} \gamma_{3}(s) d s
$$

for all $x, y \in X$, where $\gamma_{1}, \gamma_{2}, \gamma_{3} \in \Lambda$ and satisfy condition (2.2). If $T$ and $F$ are weakly compatible, then $T$ and $F$ have a unique fixed point.

Proof Follows from Theorem 1 by taking $\psi(t)=\int_{0}^{t} \gamma_{1}(s) d s, \alpha(t)=\int_{0}^{t} \gamma_{2}(s) d s$ and $\beta(t)=$ $\int_{0}^{t} \gamma_{3}(s) d s$.

Taking $\gamma_{3}(s)=(1-k) \gamma_{2}(s)$ for $k \in[0,1)$ in Theorem 2 , we obtain the following result.

Corollary 1 Let $(X, d)$ be a Hausdorff and complete g.m.s. and let $T, F: X \rightarrow X$ be selfmappings such that $T X \subseteq F X$, and FX is a closed subspace of $X$, and that the following condition holds:

$$
\int_{0}^{d(T x, T y)} \gamma_{1}(s) d s \leq k \int_{0}^{d(F x, F y)} \gamma_{2}(s) d s
$$

for all $x, y \in X$, where $\gamma_{1}, \gamma_{2} \in \Lambda$ and $k \in[0,1)$ and satisfy condition (2.2). If $T$ and $F$ are weakly compatible, then $T$ and $F$ have a unique fixed point. 


\section{Competing interests}

The authors declare that they have no competing interests.

\section{Authors' contributions}

All authors contributed equally and significantly in this research work. All authors read and approved the final manuscript.

\section{Author details}

${ }^{1}$ Department of Mathematics, Faculty of Science, University of Gazi, Teknikokullar, Ankara 06500, Turkey. ${ }^{2}$ Department of Mathematics, Muş Alparslan University, Muş, 49100, Turkey. ${ }^{3}$ Department of Mathematics, Faculty of Science and Arts, University of Amasya, Amasya, 05100, Turkey.

Received: 1 August 2012 Accepted: 29 April 2013 Published: 16 May 2013

\section{References}

1. Branciari, A: A fixed point theorem of Banach-Caccioppoli type on a class of generalized metric spaces. Publ. Math. (Debr.) 57, 31-37 (2000)

2. Das, P: A fixed point theorem in a generalized metric space. Soochow J. Math. 33(1), 33-39 (2007)

3. Das, P, Lahiri, BK: Fixed point of a Ljubomir Ćirić's quasi-contraction mapping in a generalized metric space. Publ. Math. (Debr.) 61, 589-594 (2002)

4. Das, P, Lahiri, BK: Fixed point of contractive mappings in generalized metric spaces. Math. Slovaca 59(4), 499-504 (2009)

5. Azam, A, Arshad, M: Kannan fixed point theorem on generalized metric spaces. J. Nonlinear Sci. Appl. 1(1), 45-48 (2008)

6. Fora, A, Bellour, A, Al-Bsoul, A: Some results in fixed point theory concerning generalized metric spaces. Mat. Vesn. 61(3), 203-208 (2009)

7. Mihet, D: On Kannan fixed point principle in generalized metric spaces. J. Nonlinear Sci. Appl. 2(2), $92-96$ (2009)

8. Samet, B: A fixed point theorem in a generalized metric space for mappings satisfying a contractive condition of integral type. Int. J. Math. Anal. 3(26), 1265-1271 (2009)

9. Samet, B: Discussion on: a fixed point theorem of Banach-Caccioppoli type on a class of generalized metric spaces by A. Branciari. Publ. Math. (Debr.) 76(4), 493-494 (2010)

10. Sarma, IR, Rao, JM, Rao, SS: Contractions over generalized metric spaces. J. Nonlinear Sci. Appl. 2(3), 180-182 (2009)

11. Lakzian, $\mathrm{H}$, Samet, B: Fixed point for $(\psi, \varphi)$-weakly contractive mappings in generalized metric spaces. Appl. Math. Lett. 25(5), 902-906 (2012)

12. Di Bari, C, Vetro, P: Common fixed points in generalized metric spaces. Appl. Math. Comput. 218(13), 7322-7325 (2012)

13. Choudhury, BS, Kundu, $\mathrm{A}:(\psi, \alpha, \beta)$-weak contractions in partially ordered metric spaces. Appl. Math. Lett. 25(1), 6-10 (2012)

14. Jungck, G, Rhoades, BE: Fixed point for set valued functions without continuity. Indian J. Pure Appl. Math. 29(3), 227-238 (1998)

doi:10.1186/1687-1812-2013-131

Cite this article as: Işık and Türkoğlu: Common fixed points for $(\psi, \alpha, \beta)$-weakly contractive mappings in generalized metric spaces. Fixed Point Theory and Applications 2013 2013:131

\section{Submit your manuscript to a SpringerOpen ${ }^{\circ}$ journal and benefit from:}

- Convenient online submission

- Rigorous peer review

- Immediate publication on acceptance

- Open access: articles freely available online

High visibility within the field

- Retaining the copyright to your article 